\title{
Gravity Scaling of a Power Reactor Water Shield
}

Robert S. Reid and J. Boise Pearson

NASA Marshall Space Flight Center: Morris Road, Huntsville, AL 35812; Robert.S.Reid@nasa.gov

\section{INTRODUCTION}

A similarity analysis on a water-based reactor shield examined the effect of gravity on free convection between a reactor shield inner and outer vessel boundaries. ${ }^{1}$ Two approaches established similarity between operation on the Earth and the Moon: 1) direct scaling of Rayleigh number equating gravity-surface heat flux products, 2) temperature difference between the wall and thermal boundary layer held constant. Nusselt number for natural convection (laminar and turbulent) is assumed of form $N u=C R a^{n}$.

\section{FORMULATION}

Fig.1. shows a drawing of a reactor-water shield assembly. The radiation shield outer vessel is a metal tank 1-m diameter and 2-m tall. The inner vessel that contains the core, also a metal, is $0.6-\mathrm{m}$ diameter and $0.8-\mathrm{m}$ tall. A significant proportion of the heat transfer between the inner and outer vessels is by a natural circulation of water rising on the inner vessel and falling on the outer vessel surface. Conduction and radiation terms are gravity independent, are smaller than the natural convection term, and thus are not considered here. Volumetric heating of the water by nuclear radiation is small compared to heat transfer from the inner vessel. The pressurized water volume inhibits nucleate boiling onset. For simplicity, only heat transfer from vertical surfaces is considered. A constant heat flux boundary condition exists at the inner vessel surface. The outer vessel will be likely cooled by a heat pipe array producing a mixed boundary condition. To make analysis tractable, a constant heat flux boundary will be assumed to exist on the outer vessel surface.

\section{Approach \#1: Similarity Based on Rayleigh Number}

The Rayleigh number describes a balance of buoyant to viscous forces and for a constant heat flux boundary on a vertical surface is:

$$
R a_{H^{*}}=\frac{g \beta q^{\prime \prime} H^{4}}{\alpha v k}
$$

where $g$ is the acceleration due to gravity, $\beta$ is fluid compressibility, $q^{\prime \prime}$ is the heat flux at the surface, $H$ is the height of the heated surface, and $\alpha, v, k$ are the thermal diffusivity, kinematic viscosity, and thermal conductivity of the fluid, respectively. ${ }^{2}$ Since fluid properties and geometry of the shield remain similar between the environments the ratio of surface heat flux becomes a simple gravity ratio:

$$
\frac{q_{\text {Earth }}^{\prime \prime}}{q_{\text {Moon }}^{\prime \prime}}=\frac{g_{\text {Moon }}}{g_{\text {Earth }}}
$$

with value $1 / 6$. When Rayleigh numbers match, the boundary layer thicknesses are identical as are Nusselt numbers, and convective heat transfer coefficients.

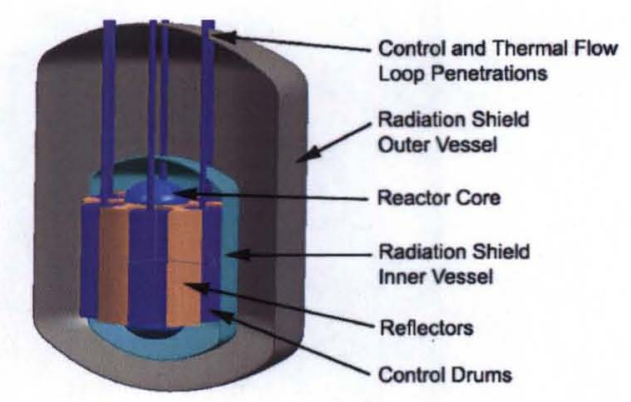

Fig. 1. Simplified Conceptual Design of a SNAP Derivative Reactor using a Water Shield ${ }^{1}$

\section{Approach \#2: Similarity Based on Temperature Drop}

Heat flux is proportional to the product of Rayleigh number (to some power) and temperature drop between the walls. The exponent depends on configuration but is often taken as $n \sim 1 / 4$ for a laminar regime and $n \sim 1 / 3$ for a turbulent regime. If temperature drop across the boundary layer is constant on Earth and the Moon, the ratio of the Earth and Lunar heat fluxes becomes:

$$
\frac{q_{\text {Earth }}^{\prime \prime}}{q_{\text {Moon }}^{\prime \prime}}=\left(\frac{g_{\text {Earth }}}{g_{\text {Moon }}}\right)^{\frac{n}{1-n}}
$$

with values 1.8 and 2.4 for the laminar and turbulent regimes, respectively. This relation signifies that to produce a given temperature drop across a boundary layer, an Earth-bound shield must operate at higher heat

\begin{tabular}{|c|c|c|}
\hline & Criteria \#1 & Criteria \#2 \\
\hline Strategy & Match $R a$ & Match $\Delta T$ \\
\hline Constraints & $R a$, fluid, geometry & $\Delta T$, fluid, geometry \\
\hline $\begin{array}{l}\text { Earth to } \\
\text { moon heat } \\
\text { flux ratio }\end{array}$ & $\begin{array}{l}\text { Factor } 0.16 \text { for all } \\
\text { conditions }\end{array}$ & $\begin{array}{l}\text { Factor } 1.8 \text { laminar } \\
\text { Factor } 2.4 \text { turbulent }\end{array}$ \\
\hline
\end{tabular}
flux. The boundary layer thickness on Earth will be half as thick as on the moon. 


\section{SIGNIFICANCE OF RESULTS}

Table I. summarizes the results of this work. The relations derived permit rational comparisons between natural convection observed for Earth-based test beds and what might be expected under reduced gravity conditions. These criteria show that matching all variables simultaneously is not possible. Earth-bound test data and numerical predictions will have to be interpreted under a variety of conditions to make reasonable predictions of shield performance under reduced gravity.

\section{REFERENCES}

1. J. B. PEARSON, E. T. STEWART, and R. S. REID, "Experimental Evaluation of the Thermal Performance of a Water Shield for a Surface Power Reactor," AIP Conference Proceedings, Volume 880, pp. 430-437, STAIF-2007 Symposium, Albuquerque, NM (2007).

2. G.D. RAITHBY, K.G.T. HOLLANDS, "Natural Convection," in Handbook of Heat Transfer, W. ROHSENOW, Ed., McGraw Hill, New York, pp. 611-613 (1985). 